


\title{
Explicitación, defensa y crítica genética a la correlación intencional en Sartre
}

\author{
Nazahed Franco Bonifaz \\ Universidad Autónoma de Zacatecas
}

\section{Resumen}

Lo que presento aquí son tres asuntos: el primero es dar cuenta de la propuesta onto-fenomenológica de Sartre como monismo fenoménico, y lo esencial de lo que ello implica; el segundo es desacreditar la crítica de Serrano de Haro contra Sartre, haciendo ver simplemente al lector que lo fundamental de la conciencia en su unidad implica un saber retencional y, que dicha unidad, es de dos tipos; por último, doy cuenta de la debilidad de la ontología de Sartre y me dedico a exhibir sus inconsecuencias.

Palabras clave: conciencia, trascendencia, libertad, voluntad, abstracto.

\begin{abstract}
What I present here are three matters: first, is to account about Sartre's onto-phenomenology proposal as phenomenic monism, and the essential thing of what it implies; second, to discredit the Serrano de Haro's criticism against Sartre, making simply to the reader to see that the fundamental of the consciousness in its unit involves a retencional knowledge and, this mentioned unit, is of two types; at last, I account for the weakness of Sartre's ontology and devote myself to exhibit its inconsistencies.
\end{abstract}

Key words: Consciousness, Transcendence, Liberty, Will, Abstract. 
Agenerales; una defensa contra las observaciones de Serrano de Haro, y algunos argumentos contra la génesis de la correlación intencional en su onto-fenomenología (argumentos que, a su vez, exigen una profundización imposible de llevar a cabo aquí). El pensamiento de Sartre, su ontología, no desarrolla directamente el estudio de la génesis correlacional en el modo en que, por ejemplo, Husserl habló de una fenomenología genética; empero, la exigencia de este tratamiento es de suma importancia si es que ha de poder ser concebida como válida una teoría de conciencia tal y como Sartre la asume en su facticidad y, más concretamente, en su unidad ek-stática temporal. Así pues, antes de entrar en tema, es necesario hacer algunas advertencias y aclaraciones al lector: 1) La dualidad de la ontología de Sartre es tratada bajo la división de fenómeno como ser del fenómeno y fenómeno de ser, esto es, entre el ser-en-sí y el sentido de la correlación intencional del parasí; pero esta dualidad no se excluye en sus términos y tampoco implica una igualdad absoluta en la referencia mutua de los implicados, sino que conforma una diferencia en tanto unidad, es decir, el ser del fenómeno y el fenómeno de ser pertenecen a regiones ontológicas distintas, que se preservan en la unidad garantizada por el sentido de la intencionalidad de la conciencia en el flujo del tiempo que devela al para-sí su constante falta de "ser". Por ello, el fenómeno se explica como monismo o unidad diferenciada. 2) Hay que tener en cuenta durante la lectura la diferencia entre seren-sí y ser-en-sí aprehendido por el para-sí, sólo de ésta manera puede entenderse el que Sartre mismo hable de "potencialidades" (no aristotélicas) o "cualidades" (no presencias metafísicas) del ensí cuando éste cae bajo la intención del para-sí. 3) El análisis genético que llevo a cabo se encuentra centrado en la negación a priori de la conciencia, ya que, al carecer de pasado (saber preterido) en el acto primigenio y primerísimo, el para-sí carece de un "valor" 
debidamente estructurado, esto es, de en-sí psíquico que, en la unidad ek-stática temporal, actúa, según Sartre, como móvil no tético de sí. Por ello, aquí la temporalidad del para-sí se refleja en el en-sí, la temporalidad reflejada es "potencialidad" del mismo en-sí siempre dentro de los límites del para-sí. 4) Hay que tener a la vista la división de los actos de libertad que Sartre otorga en la última sección de El ser y la nada en donde destaca la diferencia entre voluntad y libertad, afirmando la imposibilidad de la primera y condicionándola al cómo del resolverse de la conciencia en un fin ya determinado. La voluntad aparece sólo en ciertos casos bajo la precedente restricción. Así, se justifica la división que efectúo entre acto complejo (con voluntad) y acto simple (condicionado por la afectividad); ambos actos son, pues, libres. 5) Los argumentos contra Sartre están referidos en números romanos.

\section{Fenómeno y fundamento: el proyecto onto-fenomenológico de Sartre}

La dualidad de la ontología sartreana entre en-sí y para-sí recuerda inevitablemente aquella dualidad a la que Kant ya había concebido entre el fenómeno y el noúmeno. No es difícil entrever esta semejanza, pero hay que cuidarse y no concebir esta dualidad kantiana como una herencia sin más en la ontología de Sartre. El primer descubrimiento por el que Sartre ha de sentirse profundamente seducido es, sin duda, el del monismo de fenómeno, pues se cree que con ello, se ha podido hacer avanzar a la filosofía al reducir el existente a la serie de las apariciones que lo manifiestan. ${ }^{1}$ Para Sartre el monismo fenoménico no devela nada más que las manifestaciones

\footnotetext{
${ }^{1}$ Sartre ve esto en Heidegger, precisamente en la manera en que lo óntico puede ser sobrepasado a lo ontológico, es más, en la medida en que la condición de posibilidad del conocimiento de lo óntico es lo ontológico. Ambos, lo óntico y lo ontológico, se correlacionan.
} 
de las apariciones, pero en estas apariciones no se oculta un tipo de entidad oscura y misteriosa que no puede ser develado como el noúmeno kantiano, sino que el aparecer de su "ser" es una determinación de la cualidad objetiva del en-sí (del ser que es lo que es, la cosa) dentro de los límites de las aprehensiones inmediatas del para-sí, es lo que Sartre denomina en general como un esto: "el ser que no soy actualmente [...] es el esto" (Sartre, 2008: 262). Es por esta razón que el sartrismo no puede ser considerado, interpretado, reducido, a la famosa dualidad kantiana a la que hacíamos referencia; somos conocedores del ser-en-sí en tanto que inyectamos negatividad en él. ${ }^{2}$

La estructura interna del monismo es evidentemente el fenómeno, y éste sólo puede existir como una dualidad. Así, si la ley de la conciencia es ser conciencia de algo, ese algo es un "ser" externo que no-es la conciencia. La existencia de la conciencia sólo puede existir como presencia a sí, ésta es la condición de posibilidad de todo conocimiento y conlleva en su "ser" su propio a priori. La presencia a sí existe de modo fenoménico, y el fenómeno, he dicho, es una dualidad monista. Estas dos determinaciones del fenómeno son partes absolutamente imprescindibles la una de la otra; el fenómeno es unidad. El fenómeno de ser exige un fundamento transfenoménico, es el ser en sí, la cosa en bruto, una suerte de pasividad, y cuando aparece lo que él mismo exige en tanto que

${ }^{2}$ No hablaré de lo que Sartre le debe a Hegel con el concepto de negación y negatividad, pero es bien visible. Para Hegel la negación es "negación determinada" (Hegel, 2014: 60), que quiere decir que la negación se determina y depende de lo negado, ambos hacen referencia del uno al otro; la negatividad es el "automovimiento" de la oposición que va más allá de sí misma, transformándose. En Sartre, la negación tiene la misma función en cuanto a la mutua referencialidad de los implicados. Esta manera de entender la negación tiene orígenes en Spinoza, que denuncia a toda determinatio como negatio, la negación es propia de los modos al no afirmar cualquier naturaleza, como la Sustancia sí lo hace. A propósito puede verse la proposición VIII, escolio I de la primera parte de la Ética. 
fenómeno, su transfenomenalidad que es dotada por el ser del fenómeno, es decir, por el para-sí, entonces y sólo entonces puede hablarse propiamente de fenómeno. Pero el ser del fenómeno funda el conocimiento que de él se tiene, es decir, que el fenómeno de ser se determina a partir de algo que él no-es. La presencia a sí como modo de existencia de la conciencia es el nombre de las relaciones inmediatas entre el ser del fenómeno y el fenómeno de ser.

El modo de la descripción originaria de las relaciones entre el en-sí y para sí sólo puede encontrarse en los actos más inmediatos, ya que lo inmediato es un contacto fiel y preeminente sobre cualquier tematización ulterior. Sartre permanece fiel a Heidegger en tanto que la intuitus derivativus ${ }^{3}$ (que éste último menciona en Kant y el problema de la metafísica como modo más inmediato de contacto con las cosas) es la que posee todo el peso privilegiado donde han de buscarse las condiciones de posibilidad de la experiencia - para decirlo con Kant- o las condiciones del conocimiento de lo óntico - para decirlo con Heidegger-. Aunque para éste último hay también, sobre todo, conocimiento ontológico. La inmediatez de la conciencia que proclama el sartrismo consiste en existir como pre-reflexiva, como trascendiéndose en el mundo al ir más allá de sí, la conciencia toma por objeto al en sí que se devela como lo trascendente; por eso en esta esfera no existe el ego entendido como permanencia y reflexividad y, por tanto, tampoco ha de existir lo psíquico. Aquí nada opaca la conciencia, es pura traslucidez; ésta es la tesis sostenida en La trascendencia del ego. No obstante, el hecho de que la conciencia irrumpa de golpe en una pastosidad de "ser", en el mundo, entre las cosas, lo cambia todo. ${ }^{4}$

3 "La intuición finita del ente no puede darse su objeto por sí misma. Debe permitir que le sea dado" (Heidegger, 1981: 31).

${ }^{4}$ Tanto para Sartre como para Heidegger el mundo no es una cosa o ente, sino que la llegada de la conciencia a los entes o estos hace que haya mundo: "Puesto que el mundo no es un ente pero es inherente al Dasein, es evidente que no se 
La conciencia existe en la medida en que aparece. La identidad entre "ser" y apariencia puede considerarse como el absoluto de la conciencia, esta adecuación de ser en sí y conciencia existe de la siguiente manera, para decirlo en un ejemplo: la conciencia (de) limón es el limón y el limón es la conciencia (de) limón. Tal es la estructura inmediata de la conciencia. En el limón en sí, sin presencia de la conciencia, permanece adormecida su cualidad que aparece como develadora de su "ser", acto que sucede sólo cuando se cumple el fundamento de su ser transfenoménico en tanto que fenómeno, es decir, en tanto que es nihilizado por el para sí, en tanto que hay negación prejudicativa de ser el limón; por eso el limón no puede existir sino como limón perturbado, es decir, como conciencia (de) limón y no como simple limón en el sentido en que podría afirmarse su identidad como "el limón es el limón"; el limón es, pues, la conciencia (de) limón y revés: es la presencia a sí. La presencia a sí consiste, en el terreno pre-reflexivo, en una nibilización inmediata y en un tipo de conciencia no cogitiva de sí a sí. ¿Qué significa esto, nibilización? ¿Cómo se relaciona el fenómeno y el "ser"?

"La presencia es una degradación inmediata de la coincidencia, ya que supone la separación" (Sartre, 2008: 134); es decir, se es presente a la conciencia lo que ella no-es, ese estar presente como no siendo la cosa es lo que se define como intuición, ${ }^{5}$ que es ade-

puede pensar dicha relación como la relación entre un ente, el Dasein, y otro ente, el mundo" (Heidegger, 2007: 136). Como lo recuerda Simone de Beauvoir, Sartre es "fiel en este aspecto a la idea heideggeriana según la cual la realidad humana se anuncia su propio ser a partir del mundo" (Beauvoir, 1969: 13). Sin embargo, el modo de entender términos como trascendencia y libertad-que tienen que ver con la explicación del concepto de mundo y de fundamento en ambos autores- difieren de acuerdo a la originalidad de Sartre frente a Heidegger con los análisis de la negatividad y la nada aplicados a ellos.

${ }^{5}$ El sentido de la intención quedará mejor explicado en el siguiente apartado como intención en el porvenir. 
más la que posibilita el conocimiento del para-sí. La teoría de la facticidad del para-sí mantiene el principio de que la negación que le es propia, es "relación tal entre dos seres que aquel que es negado del otro cualifica a éste [...] sólo el para-sí puede ser determinado en su ser por un ser que no es él" (Sartre, 2008: 253). Es la presencia a sí. Existir a distancia de sí es ser presencia a sí, y se existe de este modo en todo momento de vida de la conciencia.

Ya he dicho que el cogito pre-reflexivo existe como conciencia (de) limón no tética de sí, la conciencia se dirige a un objeto trascendente, al limón, y no a ella misma; esto es existir a distancia de sí ya que la atención de la conciencia es puesta en el objeto que no-es ella y que, sin embargo, la conciencia es conciencia (de) sí cuando es conciencia de un objeto trascendente (el limón). Si la conciencia no fuese conciencia de ser conciencia (de) limón la conciencia sería algo inconsciente, una conciencia-inconsciente, lo que es absurdo y contradictorio ya que toda conciencia es conciencia de algo, y este algo se refleja para sí como siendo conciencia (de) sí. Este acto también comporta una nibilización en tanto que la presencia a sí, en su propio "sí", indica la posibilidad de que la conciencia exista como testigo de sí misma, que se consulte a sí misma en una relación de sí; relación que es por lo demás ideal en la reflexión bajo la díada fantasma reflejo-reflejante o el circuito de ipseidad cuyo objeto es el de ser "presente-ausente" (Sartre, 2008: 266). En lo pre-reflexivo el para sí remite a sí y no sólo a un objeto trascendente: "el ser de la conciencia en tanto que conciencia consiste en existir a distancia de sí como presencia a sí, y esa distancia nula que el ser lleva en su ser es la Nada" (Sartre, 2008: 135). Por esta razón, la conciencia, para Sartre, consiste en hacerse; nada está dado, la existencia precede a la esencia.

La conciencia se devela ante todo y sobre cualquier cosa como un "ser" que es capaz de soportar en su "ser" su propia nada; la conciencia se determina por un "ser" que ella no es, y sólo lo es en el 
modo de identidad negada como para-sí-en-sí sin que la conciencia llegue a identificarse con el en-sí (ya que el para-sí no puede ser su propia coincidencia porque no puede ser identidad plena consigo misma, si no, sería convertida repentinamente en en-sí, lo que no puede ser, en cosa), la existencia de la conciencia, su hecho, implica su esencia; la conciencia se proyecta en sus posibles al ser un "ser" ek-stático temporal: el ser de la conciencia es su libertad en la medida en que actúa. El para-sí es acción.

Es imposible describir aquí todos los funcionamientos que la conciencia, según Sartre, lleva a cabo. Sin embargo, es importante resaltar algunas aclaraciones que pueden servir de hilo conductor general en la problemática del monismo fenoménico: "el para-sí, en efecto, no es sino la pura nihilización del en-sí: es como un agujero de ser en el seno del ser" (Sartre, 2008: 829). Esto quiere decir que sólo en la relación del para-sí con el en-sí puede surgir una "catástrofe", el aparecer del para-sí en el "ser" significa el aparecer del mundo como fenómeno. Lo que el para-sí nihila del en-sí es un "ser" individual y no general, con esto Sartre escapa a cualquier tipo de sustancialismo que sea el soporte del en-sí, "el para-sí no es la nada en general, sino una privación singular" (Sartre, 2008: 830). El carácter de fenómeno viene entonces al "ser" por el parasí, pero esto no quiere decir que el para-sí sea el fundamento de "ser" de la nada de su "ser", sino que "el 'ser' posee prioridad sobre la nada” (Sartre, 2008: 830). El para-sí no puede fundar su presencia en el mundo, sólo funda su existencia, "el ser-en-sí puede fundar su nada pero no su ser; en su descompresión, se anihila en un para-sí que se hace, en tanto que para-sí, su propio fundamento; pero su contingencia de en-sí permanece inasible" (Sartre, 2008: 143); esto es, el para-sí es un en-sí, ya que es un "ser”, pero al ser un "ser" que en su "ser" tiene como a priori el tener-de-ser las negaciones, su "ser" inyecta la Nada en el en-sí. El para-sí es por ello un en-sí, y la forma de existir del para-sí es existir siempre 
como degradado en en-sí-para-sí. La conciencia es un "ser" que no puede existir en identidad plena consigo misma y, empero, es lo que anhela; la conciencia es deseo de ser su propio fundamento $y$, al tratar de dárselo, por la inevitable captación de un "ser" otro que la conciencia, se descompresa en para-sí, en conciencia, en suma, en posible. La facticidad del para-sí consiste, pues, en que la conciencia no es su propio fundamento en tanto que presencia al mundo sino que se limita a fundar su propia nada, su existencia. "Así, la conciencia no puede impedirse a sí misma ser, y empero es totalmente responsable de su 'ser"' (Sartre, 2008: 143).

De modo que el fenómeno no adviene sin fundamento y viceversa, el hecho de que exista la fenomenicidad es porque ha venido al "ser", al en-sí, el fundamento: la conciencia como fundando su nada de "ser" mediante una fenomenicidad monista-diferenciada.

\section{La mala recepción por parte de Serrano de Haro} a la onto-fenomenología de Sartre; breves demostraciones de las inconsecuencias en la ontología de El ser y la nada

En esta parte no trataré la crítica al ego trascendental husserliano por parte de Sartre, ${ }^{6}$ sino que más bien he de defenderlo ante los

${ }^{6}$ En Husserl es la subjetividad trascendental la que constituye los hábitos, el yo es un sustrato de habitualidades, "este yo centrípeto no es un vacío polo de identidad (...) sino que, en virtud de una ley de la "génesis trascendental» gana una nueva propiedad duradera con cada acto de un nuevo sentido objetivo irradiado por él" (Husserl, 1986: 120-121). Los actos de conciencia tienen vigencia, y el momento presente de un acto encuentra su vigencia en lo que la conciencia ha aprendido y sabe del objeto al que mienta en el presente vivo. Los hábitos pueden decirse de dos maneras, en tanto que son poseedores de un saber y tal posesión convertida en potencia presente que hace posible que la conciencia sea conciencia de un objeto, que sea intencional. Dejaré de lado la crítica contra el ego trascendental husserliano y observemos que, esta llamada subjetividad trascendental en su relacionarse con objetos intencionales, más específicamente, 
ataques mal recibidos y peor formulados por Serrano de Haro; porque a Sartre no se le ha entendido y es incluso verdadero afirmar que tampoco se le ha leído o, más bien, se le ha leído con los ojos de un Husserl que pretenden, aquellos que leen inconfesadamente mal la ontología de Sartre, reducirlo a los límites de iure del conocimiento que la fenomenología trascendental pudiera otorgar. Lo que aquí abordo, es una defensa a concretamente dos aspectos críticos fundamentales que se le han atribuido al existencialista, daré razón de la imposibilidad de destruir legítimamente su ontología, en suma, daré voz y argumento a aquél que no ha podido defenderse contra los ataques que a continuación presento en su brevedad (no podría ser más que de este modo, pues los argumentos anti-sartreanos son sólo cenizas que se han confundido con un fuego destructor).

Lo que este autor reclama en la introducción a la edición española de La trascendencia del ego es que, según Sartre, ha caído con su teoría de la conciencia irrefleja en una aporía, pues las alternativas o consecuencias que se derivan de ella son las siguientes:

o bien cada acto que se dirige al objeto se coloca siempre de nuevas ante él, en relación de captación y posición activas [...] o [...] es que habrán emergido mecánicamente los actos rememorativos que susurran que ya antes se hizo muchas veces esta misma operación, que siempre fue válida, etc. [la operación $2+2=4$ que propone Sartre como ejemplo de unidad de conciencia en el mismo objeto trascendente $2+2=4$ ] Sólo que en esta segunda opción la

con objeto reales o existentes en cuanto referidos al mundo, en su función de ser capaz bajo una ley de la «génesis trascendental» de poner objetos, se diferencia de la conciencia irrefleja a la que alude Sartre hasta el cansancio por el sentido de la correlación intencional, mismo que depende, en Husserl, en un qué o fenómeno idéntico inexistente y, en Sartre, en la nada que refleja el tiempo y contingencia de la conciencia en su relacionarse con objetos existentes. 
conciencia entregada al objeto sí se transforma, en notable medida, en conciencia reflexiva (Serrano de Haro, 2010: 21).

No obstante, para Sartre la conciencia irrefleja es, a su vez, la conciencia interna del tiempo que se unifica a sí misma mediante las retenciones y una serie de intencionalidades; sin embargo, esa misma conciencia, en la que Sartre sienta su ontología cuyo modo de "ser" es de carácter impersonal, también posee otra unidad, unidad que es síntesis de todas las conciencias pasadas, presentes y futuras, tal unidad se encuentra en el objeto trascendente al que apunta la conciencia irrefleja. En efecto, así es:

el objeto es trascendente a las conciencias que lo captan, y es en él donde se encuentra la unidad de ellas. Se replicará que, sin embargo, hace falta un principio de unidad en la duración para que el continuo flujo de las conciencias sea susceptible de poner fuera de él objetos trascendentes. Las conciencias tienen que ser síntesis perpetuas de las conciencias pasadas con la conciencia presente [...] es la conciencia la que se unifica a sí misma [...] el que dice "una conciencia", dice toda la conciencia (Sartre, 2010: 38-39).

Según parece, la conciencia irrefleja en todas sus determinaciones posee una doble unidad, misma que se encuentra en lugares bien diferentes, se podría decir polos opuestos, uno es dado en la conciencia y otro en el objeto al que apunta. Las unidades de la conciencia se encuentran tan íntimamente relacionadas que una no puede ser sin la otra, y la manera que tienen-de-ser cada cual en su coexistencia es lo que permite tener cualquier experiencia, la doble unidad es condición de posibilidad del conocimiento. Las determinaciones de la conciencia dependen de dos estructuras que se complementan y que, al volverse, en el supuesto hipotético de que pudiera darse el caso, una imposible o nula, la otra necesariamente devendría igual; es decir, que la muerte de una implica la 
de la otra. Esto sucede así puesto que la conciencia irrefleja que defiende Sartre como primacía absoluta no es, no podría ser, un cascarón vacío como parece entender Serrano de Haro. Si existe el reproche o la crítica a Sartre sobre que la conciencia irrefleja ha de ponerse siempre de nuevas ante el objeto, semejante acusación sólo procede al considerar a la conciencia como vacía de todo contenido, es decir, de todo pasado con sus respectivas rememoraciones, sin historia o biografía, en una palabra, desprovista de todo saber. Esta crítica es falsa por la simple razón de que la conciencia irrefleja se encuentra grávida de saber y de pasado, pero tal conciencia no sólo tiene necesidad de unificarse a sí misma en su duración, sino que tiene necesidad de encontrar su unidad -que es al igual que la anterior inmediata y que surge en la corriente de la existencia de la conciencia sin más- en el objeto trascendente al que apunta.

La descripción originaria sartreana de conciencia propone al saber como condición para que la conciencia sea precisamente intencional:

la imagen está definida por su intención. La intención es lo que hace que la imagen de Pedro sea conciencia de Pedro. Si se toma esta intención en su origen, es decir, cuando surge de nuestra espontaneidad, implica ya, por muy desnuda que se suponga, cierto saber: es, por hipótesis, el conocimiento de este Pedro (Sartre, 2005: 85).

Lo anterior permite entrever claramente, teniendo en cuenta que la conciencia imaginante es una conciencia irrefleja, que la determinación imaginante de la conciencia en tanto intencional -que evidentemente no podría ser de otra forma porque la imagen es un correlato que la conciencia aprehende en una determinada manera de darse- posee como estructura fundamental la unidad que permite proponer la tesis irrealizante o imaginaria; tal unidad es la unidad de duración interna cuyo origen tiene lugar en el saber 
ganado por la experiencia. No es para nada inverosímil afirmar que cuando Sartre declara a la conciencia irrefleja como el absoluto de la existencia -ya expuse en el apartado anterior cómo es que la existencia se corresponde con el monismo diferenciado fenoménico en tanto que hay correlación entre "ser" (objetos) y apariencia (conciencia), en tanto que "ser y aparecer son lo mismo" (Sartre, 2010: 41) - está al mismo tiempo retomando las Lecciones de fenomenología de la conciencia interna del tiempo de Husserl. Así, con lo que se ha ganado como nuevo saber o saber que se actualiza, es como la conciencia presente, en tanto que ponente de un cierto saber en algún objeto trascendente, es síntesis con la conciencia pasada donde ha tenido su génesis el mentado saber.

Ahora bien, si la unidad de duración de la conciencia se corresponde con los análisis de la conciencia interna del tiempo de Husserl, ${ }^{7}$ no se ve de dónde pueda agarrar viento y fuerza la crítica de Serrano de Haro. La conciencia puede captar un correlato imaginario por el saber que la conciencia posee, la génesis de su saber es efectuada por los juegos de intencionalidad de la conciencia, "la intención no se define sino por el saber (...) una imagen no podría existir sin un saber que la constituya” (Sartre, 2005: 85). ${ }^{8}$ Serrano de Haro se equivoca en su observación: la conciencia irrefleja es temporal y posee su propia historia. ${ }^{9}$ La conciencia irrefleja

${ }^{7}$ En Husserl, es "el recuerdo primario o retención como una cola de cometa que se adhiere a la percepción del caso" (Husserl, 2010: 57); estas propiedades retencionales Sartre las somete a crítica de la que no cabe aquí hablar.

8 "Me es imposible formar una imagen sin saber al mismo tiempo que formo una imagen; y el conocimiento inmediato que tengo de la imagen en cuanto tal podría llegar a ser la base de juicios de existencia” (Sartre, 2006: 150).

${ }^{9} \mathrm{El} \mathrm{campo}$ de lo irreflejo no debe entenderse como personal por tener su propia historia biográfica, las vivencias de una determinada conciencia. La conciencia irrefleja es impersonal en la medida en que no se toma a ella misma por objeto en su desenvolvimiento inmediato, ella misma no es el foco de atención, la conciencia no es posicional de sí, es posicional de un objeto trascendente y al ser 
posee un saber que pone en el objeto y posee sus propios hábitos. ¿De dónde ha de provenir esa necesidad de que la conciencia se unifique a su vez en el objeto trascendente y no solamente en su duración?

Es en el presente concreto, en el curso de sus particulares intenciones donde la conciencia se desarrolla como unidad de sus tres ék-stasis temporales, de manera que es en el objeto trascendente donde viene a unificarse la estructura de la temporalidad del parasí. Pero el "ser" del para-sí, si se vincula con su propia libertad, ha de entenderse a ésta en el sentido de la estructura ontológica fundamental de la conciencia y no en virtud de meros actos de voluntad, tal como Sartre explica en la última sección de El ser y la nada. Así, siendo el "ser" de la conciencia su propia libertad, se afirma de ella que es pura acción:

Toda acción ha de ser intencional; en efecto: debe tener un fin, y el fin, a su vez, se refiere a un motivo. Tal es, en efecto, la unidad de los tres ék-stasis temporales: el fin o temporalización de mi futuro implica un motivo (o móvil), es decir, indica hacia mi pasado, y el presente es el surgimiento del acto (Sartre, 2008: 595).

Tal es, pues, la estructura ontológica fundamental de la conciencia. La captación intencional de un objeto trascendente sólo puede darse considerando que la conciencia es presencia a él como captando la falta que tiene-de-ser el "ser" en la negación interna del

conciencia del objeto trascendente toma conciencia de sí misma como teniendo efectivamente tal o cual objeto, tal es la ley de su existencia. Por supuesto, "mi conciencia, la de Pedro y la de Pablo se distinguen porque yo puedo decir $m i$ conciencia y Pedro y Pablo pueden hablar cada cual de su conciencia" (Sartre, 2010: 37). Hace falta un acto de segundo grado, es decir, reflexivo, para que el Yo pueda advenir, este acto consiste en la conversión espontánea de la conciencia irrefleja en reflexiva que toma por objeto a la conciencia refleja. En Sartre el Yo produce interioridad y cae de golpe sólo bajo la reflexión. 
para-sí. Es decir, que si la condición de la libertad es la acción (y no puede imaginarse una conciencia más que actuando pues ella misma es pura espontaneidad en el sentido en que es un producirse a sí misma a partir de los existentes) actuar es "modificar la figura del mundo, disponer de medios con vistas a un fin" (Sartre, 2008: 591). Lo que significa que la conciencia desde la concepción del acto se retira del mundo para "abordar francamente el del no-ser" (Sartre, 2008: 592).

Una intención presente no es solamente presente a la presencia del objeto o ser-en-sí sino que la conciencia tiene siempre la necesidad de poner "un estado de cosas ideal como una nada presente; por otra parte, que ponga la situación actual como nada con respecto a ese estado de cosas ideal" (Sartre, 2008: 594). La conciencia irrefleja como circuito de ipseidad tiene, en un mismo movimiento intencional en el presente concreto, la estructura unitaria de motivos, móviles y fines. El motivo es la "captación objetiva de una situación determinada en cuanto esta situación se revela, a la luz de cierto fin, como apta para servir de medio para alcanzarlo" (Sartre, 2008: 608), el motivo es nihilizado, aislado y trascendido hacia la potencialidad que le es propia, es por principio objetivo de un estado de cosas presentes a la conciencia. El móvil es un "hecho subjetivo" (impulso patológico, un sentimiento particular, miedo, vergüenza, etc., es el "valor") (Cfr. Sartre, 2008: 608). El fin, por su parte y en complementariedad con el motivo y móvil, es "un estado de cosas que aún no es [...] una nada" (Sartre, 2008: 610611). La estructura de la conciencia libre es entonces como sigue:

La captación del móvil [el miedo presente que sólo tiene sentido fuera de sí en un fin ausente que puede ser la conservación de una vida a la que capto como en peligro, todo ello como conciencia no posicional de sí] remite enseguida al motivo correlato suyo [efectivamente como conciencia posicional de motivo que se identifica con lo objetivo] [...] el móvil, aún petrificado y fijado en en-sí 
[el miedo], mantiene al menos como significación el haber sido conciencia de un motivo, es decir, descubrimiento de una estructura objetiva del mundo [...] como el móvil es en-sí y el motivo tiene carácter objetivo, ambos se presentan como una pareja sin diferencia ontológica [...] nuestro pasado se pierde en medio del mundo (Sartre, 2008: 612).

Hay en cada acto intencional la presencia de la unidad indisoluble entre móviles y motivos pasados y presentes, fines futuros que surgen en el seno de una libertad "que es allende los motivos, móviles y fines” (Sartre, 2008: 614). De manera que la famosa expresión "estamos condenados a ser libres" quiere decir que la conciencia no puede existir sino como acción, es decir, que la conciencia en su unidad ek-stática fundamental no puede ser sino intencional-trascendente. La libertad, se entiende, no es un acto de voluntad. De hecho, la voluntad supone "el fundamento de una libertad originaria para poder constituirse como voluntad" (Sartre, 2008: 604), supone pues la unidad ek-státicatemporal del para-sí. En la voluntad los fines ya están puestos al igual que los móviles:

lo que queda por decidir en cada instante es la manera en que me conduciré respecto de ellos, o dicho de otro modo, la actitud que tomaré [...] [la voluntad es] la decisión que sucede a una deliberación con respecto a móviles y motivos (Sartre, 2008: 605-606).

En la voluntad los dados ya están echados, por lo que creer que mi voluntad autónoma escoge un tal fin en lugar de otro es caer en una ilusión, sería poner deliberadamente dentro del para-sí un en-sí tal que sería lo escogido por el propio para-sí rompiendo así su espontaneidad al dotarlo de pasividad psíquica en el flujo de la trascendencia. Para Sartre sólo hay un tipo de voluntad autónoma y ésta se corresponde con la deliberación de cómo se comportará la conciencia en vistas a un fin que la conciencia no ha deliberado 
sino que ha surgido de la potencialidad de la cosa. Aunque volveré sobre ello, ahora daré el siguiente argumento que desarma la concepción voluntarista sartreana dentro de la teoría de la libertad al romper la unidad temporal del para-sí: ${ }^{10}$

El modo de conducirse a un fin es solamente de dos tipos: racional y pasional. Llamaré "acto complejo" al proceso en que la voluntad racional se conduce hacia un fin ya puesto por la libertad original. La complejidad del acto es como sigue: hay una conciencia irrefleja que se intenciona efectivamente a un motivo presente (lo objetivo del estado de cosas) y capta su sentido a un fin ausente como nada. Existe en el presente y en perfecta comunión con lo anterior el móvil no tético de sí que es lo psíquico (hecho subjetivo) no tematizado que ha de moverse con vistas a un fin $y$, a su vez, para que haya existido la puesta de un fin a partir de un motivo con el móvil presente debe existir ya móvil y motivo pasados. A todo esto se le añade que una vez puesto el fin, sin decisión autónoma por parte del para-sí, hay un acto reflexivo que "exige la aparición de una conciencia reflexiva que capte al móvil como cuasi-objeto [...] a través de la conciencia refleja" (Sartre, 2008: 615), de manera que la reflexividad voluntaria "practica la epojé del motivo, lo mantiene en suspenso" (Sartre, 2008: 615).

La voluntad reflexiva (conciencia de segundo grado) toma por objeto, pues, al móvil que no era captado de modo posicional (es decir que no es un objeto por sí) en la conciencia irrefleja pero que estaba ahí implícitamente, así, el móvil o hecho subjetivo no es solamente un "ser" que tengamos en el modo del "era" (era miedoso pero ya no lo soy más), sino que la retoma de un móvil anterior (ser miedoso) en su rechazo o apreciación nueva "no se distingue del proyecto por el cual me asigno nuevos fines" (Sartre, 2008: 613). La deliberación voluntaria-racional y autónoma sólo tiene sentido cuando existe un acto de reflexividad sobre los móviles-psíquicos, y en tal acto la voluntad sólo puede intervenir para una decisión ya tomada. No obstante, el cambio de intención de la con-

${ }^{10}$ Sartre no se encarga propiamente del estudio de la voluntad, a lo que aquí me atengo es a criticar la tesis sostenida: el hecho de que la voluntad-reflexiva sólo tiene autonomía para determinar el modo de ir a un fin. 
ciencia irrefleja en su unidad ek-stática temporal entre móviles motivos y fines, a la conciencia reflexiva en que se da cuenta de los móviles y los posiciona como objetos para decidir sobre la manera de alcanzar un fin, es un salto o cambio radical que la conciencia no puede llevar a cabo sin quebrar su unidad. Así es, en efecto, pues si la reflexividad o deliberación autónoma de conducirse a un fin ya puesto indica un control o conducción de sí de la conciencia en que no ha de dejarse llevar por un impulso pasional a tal fin, entonces tiene que hablarse aquí de correlación entre la conciencia que tiene por objeto al móvil y la que tiene por objeto al fin, ya que han de correlacionarse si se pretende influir de modo efectivo en la persecución efectiva de un fin hasta su llegar a término o realización. La conciencia de móvil como reflexividad y expresión única de la autonomía del para-sí delibera el modo de conducción al fin, pero el fin al ser un allende-el-ser como potencialidad propia de la cosa dentro de la aprehensión del para-sí (en seguida se verá con más detalle) no pertenece a él, pues el fin es una ausencia, lo que le falta a la negación del para-sí para ser negación en-sí. El objeto o fin de la conciencia donde se desarrolla la libertad original es trascendente, y al ser éste el fundamento de la voluntad, "fundamento rigurosamente contemporáneo de la voluntad o de la pasión" (Sartre, 2008: 605), el modo reflexivo-voluntario se correlaciona en la conducción efectiva para alcanzar un fin, que es inalcanzable porque un fin realizado implica la toma de otro fin al volverse el primer fin en móvil-motivo pasados en la forma del "era"; el para-sí es pura falta de... no es ni puede ser en-sí que es lo que es.

El quiebre de la unidad de la conciencia en este acto correlativo de la voluntad en la persecución de un fin, se encuentra en la contradicción de que la conciencia irrefleja tiene por objeto al motivo (presente) y fin (como negación complementaria o sentido del motivo presente); a la vez, la conciencia reflexiva tiene por objeto al móvil-psíquico pretendiendo influir en el objeto motivo-fin del campo de lo irreflejo. Si no fuera así, si la conciencia reflexiva no tuviera además al fin por el sentido de su objeto-móvil, no habría razón de postular a la voluntad, ya que la voluntad y su objetomóvil adquieren su sentido en vistas a un fin. La necesidad de 
la correlación de lo reflexivo en lo irreflejo proviene entonces de que la voluntad sólo tiene sentido por la puesta del fin en el que se decide con autonomía el modo de alcanzarlo. Así, la conciencia sería a la vez, en el mismo campo de lo trascendente-irreflejo -pues es aquí de donde proviene y donde se resuelve cada acto libre-, reflexiva e irreflexiva, ambas referidas y persiguiendo a un mismo objeto que es el fin como su sentido. Sin embargo, ambas conciencias, la reflexiva e irrefleja, se encontrarían referidas a un mismo objeto desde génesis diferentes y declarándose, sin embargo, como una sola conciencia doble y contradictoria entre el Yoreflexivo (campo de lo psíquico) y lo impersonal-irreflejo (campo de lo trascendente). Dos conciencias escindidas no pueden apuntar al mismo objeto (al fin), pues sería pedir a una conciencia que se doblara en dos (irreflejo-reflexivo) para apuntar, ya constituidas desde la génesis del acto, como personal o impersonal, a un mismo objeto cuyo poder de unidad (pues la unidad de la conciencia es el objeto trascendente al que apunta) sería imposible al tratar de unificar dos conciencias absolutamente contrarias ya de antemano. No hay voluntad de la manera de conducción al fin, pues el fin como sentido de la voluntad hacia donde ella se resuelve implica correlacionar dos conciencias contrarias en un mismo objeto. I) $\mathrm{Si}$ ambas conciencias se unificaran en el fin, sería menester que la conciencia reflexiva dejara de tomar por objeto al móvil para captar como sentido al fin, pero entonces por ello mismo dejaría de ser reflexiva, pues el fin es develado por la conciencia irrefleja; II) lo reflexivo no puede tener por objeto al fin pues ello implica la conversión a ser irrefleja y, con ello, a perder la voluntad; III) si lo reflexivo sólo tomara por objeto al móvil-psíquico no tendría un sentido el hecho de su aparecer, pues no habría dónde correlacionarse: el sentido de la voluntad es decidir sobre la conducción hacia el fin; por último, si lo reflexivo tomara por objeto al móvil y al fin como su sentido, entonces sería igualmente imposible, pues- 
to que el fin aparece solamente a la conciencia irrefleja, convertido en reflexo, no habría dónde correlacionar el móvil ya que el fin dejaría de ser nada-ausente-trascendente para convertirse y revelarse repentinamente como puro en-sí psíquico, ${ }^{11}$ entonces habría una pretendida correlación entre dos objetos igualmente psíquicos y el fin-ausente-trascendente dejaría de tener importancia, pero precisamente es de suma importancia al ser la textura de "ser" de la conciencia; habría pura correlación psíquica, pero esto no es la libertad. Hay que concluir, por tanto, que en el "acto complejo" de la libertad donde hay irrupción de lo reflexo no puede haber unidad; la voluntad así entendida es imposible. ¿Puede el objeto trascendente como fin-ausente unificar a la conciencia irrefleja sin irrupción de la conciencia reflexiva? Un examen más minucioso puede aclarar que dicho acto libre fundamental de la conciencia no satisface a las explicaciones de la génesis correlacional.

Llamaré "acto simple" al acto libre de la conciencia en que no hay reflexividad y que se resuelve de manera pasional o afectiva. La estructura de la conciencia es la misma que la del "acto complejo", salvo que la voluntad en su aparecer reflexivo-refleja desaparece para dar lugar a una resolución libre a partir de la afectividad. Este modo de concebir la libertad es el fundamental para Sartre, pues en ella se encuentra la conciencia irrefleja en su pura traslucidez. No obstante, si el fin es donde adquiere el sentido toda captación intencional-trascendente, es preciso describir de dónde proviene.

${ }^{11}$ Para Sartre, la esfera psíquica está dada en la reflexión y es constituida por los estados, las acciones y cualidades que son objetos en-si y por ello trascendentes, además aquí se constituye el "yo" como unidad de esas unidades que son objetos en-sí psíquicos; mientras que los objetos trascendentes de lo irreflejo son un esto concreto, cosas que anuncian sus cualidades durante la captación del para-sí, por lo que las ausencias son también trascendentes de este tipo de conciencia siendo ellas mismas "potencialidades" de la cosa. Tal es la diferencia esencial entre los objetos de estos tipos de conciencia: la procedencia de los objetos, unos de la reflexividad, otros de las cosas en comunión con la conciencia. 
El fin aparece por la correlación entre conciencia y objeto, pero no aparece, es importante entenderlo, ni pertenece propiamente sólo a la conciencia o al objeto; es decir, se da en la unidad diferenciada de una conciencia que es tiempo y un objeto que tiene por cualidad reflejarlo y aparece sólo a un "ser" que es allende sus posibilidades en comunión con un objeto que posee sus propios abstractos, abstraídos por el ser abstrayente que es el para-sí. Esto quiere decir que

en la medida en que me hago ser negación del esto, huyo de esta negación hacia una negación complementaria cuya fusión con la primera deberá hacer aparecer al en-sí que soy; y esta negación posible está en conexión de ser con la primera; no es una negación cualquiera, sino precisamente la negación complementaria de mi presencia a la cosa (Sartre, 2008: 275).

Es lo que en el apartado anterior se identificó como "presencia a sí". Sin embargo, la conciencia no es nunca sólo presente a un esto, que es la cosa que no-es la conciencia en la intención actual, sino que siempre es presente a una presencia del tipo esto que posee cualidades. La cualidad del esto como en-sí que es lo que es, fuera de la captación intencional, sólo es un puro ser-en-sí de identidad indiferenciada. El esto como en-sí que es, teniendo-de-ser sus cualidades, determina al para-sí por medio de la negación interna en que el para-sí existe como negando ser las cualidades del esto. La cualidad es objetiva y "no es sino el ser del esto" (Sartre, 2008: 267), es "lo inmediatamente fuera de alcance, lo que, por definición, nos indica a nosotros mismos como vacío; es decir, aquello cuya contemplación no puede sino acrecentar nuestra sed de ser" (Sartre, 2008: 269); ${ }^{12}$ No obstante, para que la cualidad aparezca

${ }^{12}$ Se acrecienta la sed de "ser" por el hecho de que la conciencia, al no poder coincidir consigo en una pura identidad, se forma siempre como "falta de...". 
es menester que "haya ser para una nada que por naturaleza no sea el ser" (Sartre, 2008: 268), por lo que "el ser no es en-sí cualidad [...] la cualidad es el ser íntegro en cuanto se revela en los límites del "hay" (Sartre, 2008: 268). ${ }^{13}$ La conciencia en Sartre, en este sentido, es una nada que se va constituyendo a sí misma por medio de lo que ella no-es, del en-sí con sus cualidades. Pero la negación presente de la conciencia hacia el esto presente implica una negación complementaria "que el para-sí tiene-de-serla como conciencia no-tética de sí y como conciencia tética de ser-allende-el-ser. El ser allende-el-ser está vinculado al esto presente" (Sartre, 2008: 276). El para-sí está, pues, siempre en relación con su porvenir durante la captación intencional de un objeto presente: "El esto se devela en la negación de un ser que se hace no ser esto, no a título de simple presencia, sino como negación por-venir a sí misma, que es su propia posibilidad allende su presente" (Sartre, 2008: 276). La cualidad presente es siempre allende-el-ser.

Se observa que el sentido de la negación presente viene por la negación allende-el-ser en un mismo movimiento, "a partir del futuro; toda negación es ek-stática” (Sartre, 2008: 276). Lo que hace aparecer al porvenir es la "permanencia" y las "potencialidades", ambos se configuran como abstractos; el fin como sentido de todas las intenciones presentes provienen de la correlación entre el abstracto y el abstrayente. La abstracción no es algo que se identifique con un proceso mental, no es un acto inmanente de la conciencia en la que hay objetos psíquicos trascendentes y la dualidad fantasma reflejo-reflejante de lo reflexivo y lo reflejo,14 más bien es lo que "infesta a lo concreto como una posibilidad fijada en el en-sí que lo concreto tiene-de-ser" (Sartre, 2008: 271). El abstracto no es un acto interiorizado de la conciencia, sino que es un trascender

${ }^{13}$ Es decir, en los límites en que hay conciencia trascendente.

${ }^{14}$ De la teoría de la reflexión y las relaciones de los objetos psíquicos-trascendentes con los del tipo irreflejo-trascendente, es algo de lo que no me encargaré. 
en tanto que presencia-ausente ${ }^{15}$ revelada al porvenir. El esto o lo concreto comporta sus propios abstractos que sólo aparecen en los límites de las aprehensiones intencionales del para-sí. No obstante, en-sí, "el ser no es ni concreto ni abstracto, ni presente ni futuro: es lo que es" (Sartre, 2008: 271).

Ahora está todo claro: la conciencia irrefleja que aprehende al esto capta un motivo presente de acuerdo a un saber pasado, es conciencia no-posicional del móvil-psíquico presente, el fin es negación complementaria al ser el sentido de la negación del motivoobjeto presente, pero el fin no es puesto por la conciencia en el objeto, sino que el objeto los posee como cualidades, éstas, son los abstractos que son de dos tipos: la permanencia y la potencialidad. Al ser de estos tipos, el objeto no está dotado de entidades misteriosas que tengan que actualizarse en una materia, la razón es que son negaciones y así son dados como ausencias en el porvenir, el mundo es un mundo de tareas.

La posibilidad que la conciencia es no téticamente como conciencia [de] poder no ser esto se devela como potencialidad del esto de ser lo que es. La primera potencialidad del objeto, como correlato del comprometimiento, estructura ontológica de la negación, es la permanencia, que viene perpetuamente a él del fondo del porvenir" (Sartre, 2008: 276).

Una mesa exige la "permanencia” de la mesa que le viene del porvenir. En la captación intencional de la mesa hay negación polimorfa del ser-mesa, ser-café, de su ser-liso, ${ }^{16}$ etc., pero es una negación que se da por perfiles, no simultáneos, aunque en cada perfil del "ser" se encuentre implicado ya todo el "ser"; la forma es

${ }^{15}$ La presencia lo es hacia la cosa presente, empero, con la cualidad de la permanencia que es porvenir, y la ausencia es la captación intencional del sentido allende-el-ser.

16 "La cualidad es" (Sartre, 2008: 269) 
el perfil que se capta del "ser" y el fondo son los demás perfiles que constituyen la negación polimorfa. Sin embargo, es importante que se medite en ello: la forma "está enteramente penetrada por el fondo, lo retiene en sí como su propia densidad indiferenciada [...] se devela como fondo interno indiferenciado y plenitud de ser [...] [es] equilibrio nihilizador de la pura y simple masividad" (Sartre, 2008: 270-271). Los perfiles o fondo que le corresponden a la aprehensión de un perfil o forma permanecen implicados pero sólo en tanto que el fondo permanece indiferenciado. La conciencia no puede captar todos los perfiles de un objeto de golpe. Así pues, la captación de la mesa como cualidad de ser-mesa y negación interna de no-ser esto, tal mesa, tiene su permanencia en su ser-puro-mesa, en la mesa-en-sí. Lo que le falta a la negación del para-sí para ser en-sí es el sentido del por-venir como permanencia, "la negación es, en el futuro, precisión de la negación presente" (Sartre, 2008: 277). El sentido de la negación del objeto presente viene por el futuro que anuncia lo que no-tengo-de-ser; el ser-mesa presente sólo tiene sentido captando su permanencia de ser-mesaen-sí que es lo que es, que aparece allende-el-ser como pura captación de identidad indiferenciada de pura permanencia de "ser"; es la negación originaria de no ser el "ser" por medio del abstracto permanente.

En la medida en que el para-sí adquiere saber y ha ganado pasado, puede captar otras cualidades o abstractos llamados "potencias" además de la "permanencia”. El para-sí, al descubrir nexos entre los objetos, capta "nuevas" potencialidades, "en tanto que el para-sí es allende el capullo, junto a la flor, la flor es potencialidad del capullo" (Sartre, 2008: 279). Es decir, conforme la conciencia va ganando experiencia y saber, devela los demás perfiles-fondo del "ser" o sus probables para ser aprehendidos como presencias trascendentes allende-el-ser. En una palabra, el abstracto de permanencia es un esto como ser que es lo que es, identidad indiferen- 
ciada de puro "ser" captado como compromiso futuro de no ser el "ser"; el abstracto como potencialidad es aquello que le hace falta al "ser" cuando hay intención del para-sí en la unidad de los tres ék-stasis temporales.

No obstante, esta estructura de la conciencia no puede satisfacer las explicaciones de cómo es que surge la génesis de la correlación intencional. Más bien al contrario, tratar de derivar a la conciencia a partir de los abstractos se vuelve imposible sin caer en aporías. Pues bien, pregunto ahora, si toda conciencia tiene un comienzo en su existencia, ¿Acaso la conciencia primigenia puede estar ya dotada de saber? Evidentemente no, al carecer de pasado y ser fundamento de la nada de su "ser". Entonces no hay ni móviles ni motivos pasados, tampoco móvil-psíquico presente, pues éste se conforma de acuerdo al saber preterido. Quedan los abstractos y motivos o estos presentes, pero el sentido del esto se encuentra en el porvenir, por tanto, la pregunta fundamental es la siguiente: ¿Pueden los abstractos, en sus dos géneros, hacer posible la génesis de la correlación intencional, esto es, de la conciencia primigenia?

I) La captación primigenia del futuro como cualidad-abstracta del esto, en el género abstracto de la potencialidad, requiere de un saber previo a la aprehensión presente del en-sí para ser aprehendido como fin-ausente en el porvenir. De lo contrario, la conciencia al no saber nada del en-sí, no podría captar nada de su cualidadpotencia para ser puesta allende-el-ser, ya que la intención primigenia desprovista de saber es indeterminación de saber, siendo así, indeterminación en el sentido de ser carente de saber preterido, la conciencia primigenia sólo sabe por el objeto presente; es decir, no se ve de dónde, una conciencia genética o primigenia pueda develar la potencia de la flor allende-el-capullo si se carece del saber de lo que le falta al ser-capullo como su sentido; la conciencia habría debido tener por objeto en el pasado al ser-flor para producir un nexo de falta entre ser-capullo y ser-flor. Falta que es sólo del para- 
sí. A la conciencia carente de saber, si quiere conservar el develamiento de los abstractos-potencias en la génesis de la correlación, se le necesitaría revelarse de golpe todas las cualidades o el "ser" por entero en-sí como efectivamente intencional en cada cualidad-perfil en un mismo tiempo [ser-flor, ser-capullo, ser-blanco, etc.] para que bajo un mismo movimiento durante su captación intencional presente, pudiera una de esas cualidades del "ser" develarse como inactual o ausente allende-el-ser teniendo plena conciencia ya de ese "ser" ausente como nada de "ser". En suma, proponerla como fin o sentido de la intención presente. Lo que es una inconsecuencia, ya que toda intención se da por perfiles. Así, la develación de la totalidad del "ser", como decía, es íntegra en tanto que el fondo permanece indiferenciado, por lo que la conciencia no puede captar, efectivamente, en el fondo de un "ser" a un perfil ausente porque éste permanece indiferenciado. Un abstracto-potencia no aparece a la conciencia primigenia debido a la indeterminación de ésta en su saber preterido respecto del objeto trascendente, debido a la aún no formada unidad ek-stática temporal.

Queda ahora preguntarse por la posible función del abstractopermanencia en la génesis. Es fácil entrever que este género de abstracto tampoco satisface las explicaciones del funcionamiento primigenio de la conciencia tal y como Sartre desea. Si hay intención primigenia-inmediata de la permanencia entonces el "ser" debió haberse manifestado igualmente, como el caso de las potencias, en su totalidad para develar el abstracto allende-el-ser. Una pura negación del tipo de la permanencia como comprometimiento de no ser el "ser", como hace Sartre, que va hacia el futuro no dice, ni anuncia, ni hace saber nada del "ser" más que lo que se capta en el perfil presente. En efecto, se dice que la permanencia hace surgir la esfera del porvenir, pero lo que se anuncia en él es que el "ser" es lo que es y nada más; no hay aquí un saber de los demás perfiles que permanecen en el fondo del "ser", solamente hay un saber de 
"ser" como "ser" que es lo que es, un anunciar de lo que es el "ser" como no pudiendo ser la conciencia en su existencia como ese tipo de "ser". Las potencialidades que dan cuenta de los perfiles-fondo del "ser" no pueden aparecer en el acto genético, lo que se da en la permanencia es y será sólo un anunciamiento del "ser" como permanencia de que es y sólo es. Por tanto, la conciencia genética en Sartre se ve destinada a captar en la génesis correlacional un puro "ser" permanente a sí mismo, indiferenciado; la conciencia se ve limitada a captar la simpleza de no ser el "ser", pero la negación del tipo de la permanencia sin su perfil abstracto de ausencia que constituya y dé cuenta de otro perfil desde el fondo, es decir, sin correlacionarse la permanencia con las potencias, sólo es negación de no ser el "ser".

II) Es necesario ahora meditar en esto: antes que la conciencia pueda captar efectivamente a un objeto en tanto cualidad, es preciso que la cualidad haya determinado a la conciencia para que ésta ejecute la intención efectiva de captar un objeto presente como cualidad dada, pues la conciencia siendo una nada de "ser", es indeterminación de saber en el acto genético. ${ }^{17} \mathrm{La}$ conciencia, al ser indeterminación de la intención, encuentra su determinación o

${ }^{17}$ No hay, como en la fenomenología genética de Husserl, "un instinto de objetivación o de curiosidad [que] opera en la recepción de la afección o estimulo hyletico, que se presenta como un terminus a quo paraintenciones instintivas [...] El impulso de objetivación intenta captar una unidad en una multiplicidad, es decir, una unidad que se exhibe a través de los cambiantes campos de sensación. Mientras que los instintos no-objetivantes se dirigen a contenidos específicos, el instinto objetivante carece de esta orientación particular porque sólo requiere la fusión de contenidos semejantes. Se dirige a una unidad sensible, cualquiera que sea. Exhibe un interés universal por los datos de sensación, y esto lo distingue de los instintos no-objetivantes que están dirigidos a los datos de sensación en virtud de sus particulares contenidos" (Walton, 2015: 62). En cambio, para Sartre el acto irreflejo tiene por objetivo hacer que la conciencia coincida consigo misma como en-sí-para-sí, empero, fracasando en ese intento sólo puede definirse al para-sí como deseo de ser Dios (en-sí); esta meta de 
correlato en el objeto, que se dice tiene por cualidad al menos a la permanencia - pues aquí las potencialidades son inaprehensibles como he mostrado-; sin embargo, de ella sólo se capta la identidad indiferenciada como un puro-ser por medio de una conciencia temporal; luego, si hay captación no posicional de la permanencia como "identidad intemporal"18 (Sartre, 2008: 292) es menester que haya afectación de una forma o cualidad presente que otorgue la determinación o correlato a la conciencia. En caso de no haber en la génesis la correlación de la determinación del objetopresente, con la indeterminación o nada de "ser" de la conciencia, la conciencia permanecería como pura nada. La nada de "ser" de la conciencia no puede captar, en este terreno, un puro allende-elser por el hecho de que éste, siendo nada-ausente, no podría dar lugar a la presencia de la conciencia llevándola inevitablemente al encuentro de dos nadas, por lo que se vería forzada a caer en una especie de nihilismo de intenciones de la nada (conciencia primigenia) como conciencia de nada (lo ausente allende-el-ser). Si la permanencia es comprometimiento a futuro de no ser el "ser" por medio de la intención de un esto que es lo que es, entonces se dirá que la conciencia sólo se queda con lo que es, dado que el futuro sólo tiene sentido por el "ser" al que se es presente. En una palabra, la conciencia que se compromete a futuro sería simple conciencia profética que se limitaría a observar pero cuyas determinaciones de hecho serían dadas por el esto-presente. La tesis de Sartre se invierte: el presente-esto determinaría en su sentido al futuro y al pasado; ya no habría razón, en la unidad ek-stática, de un provenir dador de sentido al presente.

III) Las consecuencias e inconsecuencias se dejan exhibir ahora: si la conciencia viera en el acto genético un $\mathrm{X}$ objeto, sería nece-

coincidencia por parte del para-sí es su sentido de origen. El único a priori de la conciencia es la negación o la nada.

${ }^{18}$ Como "ser" que es lo que es. 
sario que viera en $\mathrm{X}$ por vez primera solamente a $\mathrm{X}$ como tal, es decir, que el objeto $\mathrm{X}$ inmediato se presente por vez primera a la conciencia como puro ser-X-presente para poder afirmar que hay conciencia, así sea no tética, de X como permanente identidad intemporal; sin embargo, siendo el ser-presente condición y sentido del ser-porvenir, ya se los interprete en un mismo acto, como Sartre hace, o bien en actos distintos. Lo central es ver que la cualidad ser-X-presente que rompe la indeterminación genética de la conciencia hace desechable, inútil o estéril una concepción de la permanencia como abstracto en que se da el origen del porvenir mediante el indiferenciado-comprometimiento de no ser el "ser" y donde adquiere el sentido y radica toda cualidad. Los abstractos desaparecen del papel dador de las determinaciones primigenias. No obstante, el hecho de que la conciencia no tenga por sentido inmediato una cualidad-ausente-porvenir tiene por deficiencia, dentro de la propia teoría sartreana, el hacer del en-sí el ponente de la determinación-presente que concretiza la intencionalidad trascendente en una génesis indeterminada (que lo es de una nada que va por vez primera hacia un "ser") y, con ello, lo vuelve activo. Sería afectar de en-sí puramente presente a la conciencia bajo la fórmula correlativa de coincidencia en en-sí-para-sí, lo que es imposible para Sartre.

Lo anterior ocupa una profundización que será atendida en otro lugar.

\section{Bibliografía}

Beauvoir, Simone, 1969, Jean-Paul Sartre versus Merleau-Ponty, Aníbal Leal (trad.), Buenos Aires, Ediciones Siglo Veinte,

Hegel, Georg Wilhelm Frierdrich, 2014, Fenomenología del espiritu, Joaquín Chamorro Mielke (trad.), Volke Rühle (Estudio introductorio), Madrid, Gredos. 
Heidegger, Martin, 1981, Kant y el problema del a metafísica, Gred Ibscher Roth (trad.), México, FCE.

, 2007, Hitos, Helena Cortés y Arturo Leyte (ed.), Madrid, Alianza editorial.

Husserl, Edmund, 1986, Meditaciones cartesianas, traducción de José Gaos y Miguel García-Baró (trad.), José Gaos (pról.), México, FCE.

, 2010, Lecciones de fenomenología de la conciencia interna del tiempo, Agustín Serrano de Haro (trad., intro., y notas), Madrid, Trotta.

Sartre, Jean-Paul, 2005, Lo imaginario, Manuel Lamana (trad.), Buenos Aires, Losada.

, 2006, La imaginación, Carmen Dragonetti (trad.), Madrid, Edhasa, Madrid. Losada.

,2008, El ser y la Nada, Juan Valmar (trad.), Buenos Aires, , 2010, La trascendencia del Ego, Miguel García-Baró (trad.), Agustín Serrano de Haro (pról.), Madrid, Síntesis.

Walton, Roberto, 2015, Intencionalidad y horizonticidad, Bogotá, Editorial Aula de Humanidades/Universidad Buenaventura Cali.

Recibido el 7 de agosto de 2015, Aceptado el 5 de octubre 2015 